\title{
O DIAGNÓSTICO PSICOPATOLÓGICO FENOMENOLÓGICO DA PERSPECTIVA DIALÉTICO-ESSENCIALISTA
}

\section{THE PHENOMENOLOGICAL PSYCHOPATHOLOGICAL DIAGNOSIS FROM THE DIALETIC-ESSENCIALIST PERSPECTIVE}

\author{
Guilherme Messas ${ }^{1}$ \\ Lívia Fukuda ${ }^{2}$
}

\begin{abstract}
Resumo: A partir da concepção de psicopatologia como ciência humana básica autônoma, propomos nesse artigo um método qualitativo para exploração aprofundada das vivências psicológicas transtornadas. Nossa proposta metodológica ajusta-se à realização de uma ciência psicopatologia fenomenológica dialético-essencialista, cujos conceitos fundamentais são essência, proporção dialética e estrutura. Essa perspectiva centraliza o interesse científico psicopatológico nas tensões existenciais entre o individual e o geral e entre o movimento e a estabilidade. O processo de diagnóstico psicopatológico fenomenológico, calcado na interpessoalidade, será detalhado aqui em cinco etapas. São elas: relato do sujeito e descrição psicopatológica; ressonância afetiva; terceiridade dual; intuição eidética e redução fenomenológica; e compreensão transcendental da estrutura. Acredita-se que, com o uso dessa metodologia, possamos colaborar para o aprofundamento do ato diagnóstico, assim como fornecer subsídios mais consistentes para a compreensão da prática terapêutica e a produção da agenda de pesquisa científica.
\end{abstract}

Palavras-Chave: Psicopatologia; Fenomenologia; Metodologia; Dialética; Essência.

\begin{abstract}
From the conception of psychopathology as an autonomous basic human science, we propose in this article a qualitative method for the deep exploration of disturbed psychological experiences. Our methodological proposal adjusts to the realization of a dialectic-essentialist phenomenological psychopathology, whose fundamental concepts are essence, dialectical proportion and structure. This perspective centralizes the psychopathological scientific interest in the existential tensions between the individual and the general and between the movement and the stability. The process of phenomenological psychopathological diagnosis, based on interpersonality, will be detailed here in five stages. They are: subjective report and psychopathological description; affective resonance; dual thirdness; eidetic intuition and phenomenological reduction; and transcendental understanding of structure. It is believed that with the use of this methodology, we can collaborate to deepen the diagnostic act, as well as provide more consistent subsidies for the understanding of therapeutic practice and the production of the scientific research agenda.
\end{abstract}

Keywords: Psychopathology; Phenomenology; Methodology; Dialectics; Essence.

\section{Introdução}

A despeito do inequívoco reconhecimento de seu valor nas sociedades contemporâneas, as ciências da mente padecem sob o efeito de um constante paradoxo. Por um lado, o arsenal de estratégias investigativas e clínicas disponíveis não cessa de se multiplicar e de oferecer ampla diversidade de ferramentas terapêuticas voltadas ao

\footnotetext{
${ }^{1}$ Doutor em Paiquitria (SP). Faculdade de Ciências Médicas da Santa Casa de São Paulo, São Paulo, SP, Brasil E-mail: guilherme.messas@fcmsantacasasp.edu.br

${ }^{2}$ Médica psiquiatra, Universidade de São Paulo (USP). Sociedade Brasielira de Psicopatologia Fenômeno-

Estrutural (SBPFE), São Paulo, SP, Brasil. E-mail: liviafukuda@gmail.com
} 
enfrentamento dos transtornos mentais. Por outro lado, o próprio estatuto ontológico dos transtornos mentais permanece indefinido (BANZATO; ZORZANELLI, 2014; KENDLER, 2016). Embora saibamos cada vez mais atacar o tema das alterações mentais, não temos um conhecimento consensual, até hoje, acerca da natureza do objeto psicopatológico (KENDLER, 2016). As mesmas controvérsias estabelecidas há mais de um século continuam pautando o debate atual, no qual o entendimento ontológico sobre os transtornos mentais varia de epifenômeno das funções cerebrais a construção científica arbitrária, voltada apenas ao pragmatismo clínico (BANZATO; ZORZANELLI, 2014) ou epidemiológico (KENDELL; JABLENSKY, 2003; JABLENSKY, 2016).

A discussão a respeito da natureza do objeto psicopatológico não é trivial, pois desta compreensão depende a instituição de uma metodologia com ele compatível. Esta, por sua vez, é responsável pela validação dos achados investigados empiricamente. O entrelaçamento entre a metodologia e os pressupostos ontológicos do objeto psicopatológico é tão íntimo que não se pode dizer, em última análise, que método e compreensão de psicopatologia sejam separáveis. Toda eleição metodológica, se coerente, já traz em si um pressuposto ontológico, nem sempre explicitado pelo investigador que emprega o método. É por isso que, desde os tempos de Jaspers, as Methodenstreiten (JASPERS, 1997) - as querelas do método - representam parte significativa dos debates nas ciências da mente. Portanto, é necessário que toda contribuição sobre metodologia nas ciências da mente deva iniciar-se com um esclarecimento, ainda que sucinto, de seus princípios ontológicos. Será a coerência entre método e objeto o critério de validação da contribuição do pesquisador.

A finalidade deste artigo é oferecer uma proposta metodológica coerente com uma concepção fenomenológica estrita de psicopatologia (JASPERS, 1997). Esta concepção entende psicopatologia como uma ciência humana básica autônoma, independente das demais ciências da mente (MINKOWSKI, 1999). Este entendimento assume, portanto, que o objeto da psicopatologia não é o da psicologia científica nem tampouco da fisiologia cerebral. O objeto da ciência psicopatológica é a exploração aprofundada das vivências transtornadas, o que permite ao psicólogo clínico ou ao psiquiatra a delimitação do campo no qual exerce sua atuação terapêutica. Seu objeto são as experiências psicopatológicas, ou, simplesmente, os transtornos mentais ${ }^{3}$. Entretanto, essa definição ainda é imprecisa

\footnotetext{
${ }^{3}$ Embora haja um uso corrente da palavra psicopatologia para significar qualquer transtorno mental, escolhemos empregar o substantivo "psicopatologia", no singular, apenas para a ciência psicopatológica, e
} 
para nossos propósitos. A pluralidade de entendimentos de psicopatologia fenomenológica (SPIEGELBERG, 1964; FORGHIERI, 1993; KRAUS， 2001; PETRELLI, 2005; FINLAY, 2008; AMATUZZI, 2009; GIORGI, 2009; ANDRADE; HOLANDA, 2010; FUCHS, 2010; DEPRAZ; VARELA; VERMERSCH, 2011; GALLAGHER; ZAHAVI, 2013; FEIJOO; MATTAR, 2014; GALBUSERA; FELLIN, 2014) exige que explicitemos qual a modalidade de compreensão de psicopatologia que aqui defendemos. Como ficará evidente ao longo da exposição, nossa proposta apresenta e defende um método qualitativo ajustado para a realização de uma ciência psicopatologia fenomenológica dialético-essencialista (MESSAS; TAMELINI; CUTTING, 2017), cujos conceitos fundamentais são brevemente expostos a seguir.

Para que esse gênero de exploração qualitativa seja efetuado de modo metodologicamente coerente, é necessário que seus três conceitos principais sejam elucidados. O primeiro deles é a noção de essência psicopatológica. Assumimos que toda experiência psicopatológica tenha estabilidade e autonomia suficientes para que seja possível a identificação de sua essência (MESSAS, 2012). Por exemplo, a experiência melancólica pode ser reconhecida como tal porque permanece ao longo de um intervalo considerável de tempo na existência do paciente e porque é diferente, por exemplo, da experiência obsessiva (embora também aqui haja sobreposições, que não poderemos examinar aqui). Ontologicamente, a essência de um transtorno mental é um estilo de paralisação da movimentação da existência, fazendo com que esta se fixe em demasia em um determinado ponto). Assim, a essência da melancolia seria uma excessiva restrição da existência aos papeis sociais estabelecidos (KRAUS, 1991) ou a algumas experiências corporais (STANGHELLINI, 2004). A essência da esquizofrenia, uma transformação geométrica do fluxo temporal existencial em um modo espacial de existir (MINKOWSKI, 2000) ou uma excessiva atenção da consciência a si mesma (SASS, 2014a).

Evidentemente, a autonomia da essência a ser investigada pelo método não deve ser confundida com a autonomia platônica de uma essência não inserida na realidade factual (OULIS, 2008). Uma essência psicopatológica não é uma coisa em si, idêntica a si mesma no tempo e no espaço, como a ideia de um triângulo. A essência de um transtorno psíquico é uma composição desequilibrada de proporções antropológicas, que desfavorece o pleno desenvolvimento da existência (BINSWANGER, 1977; MESSAS; TAMELINI, no prelo). Assim, na melancolia, a existência é prejudicada pela proporção

"transtorno mental" para seus objetos. O adjetivo "psicopatológico/a", por sua vez, sempre será utilizado de forma inespecífica, no sentido de qualquer transtorno mental. 
exagerada dos papeis normativamente determinados em relação aos papeis criativamente exercidos pelo sujeito. Na esquizofrenia, uma desproporcional participação do espaço na temporalidade existencial ou da introversão em relação à participação no mundo. Temos, pois, que o segundo conceito central para uma psicopatologia dialético-essencialista é a noção de proporção dialética (BINSWANGER, 1977; BLANKENBURG, 1982; KRAUS, 2003; MESSAS, 2014). Como as proporções antropológicas são móveis ao longo da vida, pode-se dizer que as essências psicopatológicas são modalidades de desequilíbrios nocivos de proporções antropológicas que existem em regime dialético constante. A proporção entre os papeis socialmente determinados e a liberdade de criação individual, como um dos exemplos possíveis de proporções antropológicas, está em constante estado de mudança, dialogando entre si em um estado de tensão dialética, cujo reconhecimento será um dos objetivos do psicopatologista. É necessário, no entanto, que o investigador conduza sua investigação ao nível em que as essências transtornadas, ou seja, os estilos de desproporção dialética, recebam um significado existencial individual. As essências e suas proporções dialéticas existem apenas encarnadas em um sentido estrutural idiossincrático. Entenderemos estrutura, portanto, como as condições de possibilidade da existência singular nas quais se insere uma formação essencial patológica. Essa noção de estrutura individual aproxima-se à noção de Dasein, tal qual utilizada por Binswanger em seus casos clínicos (BINSWANGER, 1957; BASSO, 2012).

A proposta metodológica que segue pretende capacitar o pesquisador e o clínico fenomenologicamente orientado ${ }^{4}$ a identificar as essências psicopatológicas e seu sentido nas estruturas existenciais individuais (MESSAS, 2014). Sua finalidade é, portanto, a de permitir um ato diagnóstico. No entanto, é necessária a especificação da natureza deste diagnóstico, denominado diagnóstico psicopatológico fenomenológico. O diagnóstico psicopatológico fenomenológico atinge um plano existencial profundo, que depende do conhecimento minucioso, por parte do psicopatologista, das experiências transtornadas do paciente. Esse conhecimento, calcado na experiência observacional interpessoal (MESSAS, 2010; DEPRAZ; VARELA; VERMERSCH, 2011; GALBUSERA; FELLIN, 2014), não deve ser confundido com outros diagnósticos, como o sindrômico (JABLENSKY; KENDELL, 2002) ou o operacional (APA, 2013), que nascem da necessidade de produção de um conhecimento universal, partilhável com toda a

\footnotetext{
${ }^{4}$ Embora, de modo algum, seja restrito aos pesquisadores fenomenológicos. Em tese, com o treino, todo pesquisador pode empregar este método, mesmo sem o conhecimento das categorias ontológicas a ele associadas.
} 
sociedade, denominado conhecimento de terceira pessoa (FUCHS, 2010; GARCÍA, 2017). O diagnóstico psicopatológico fenomenológico não se identifica com uma necessidade nosográfica, embora forneça elementos para ela. Vejamos um exemplo: o diagnóstico psicopatológico fenomenológico de uma essência maníaca não implica necessariamente a ocorrência de um transtorno maníaco, no sentido nosográfico do conceito. Para que este último seja identificado, é preciso que a existência seja significativamente tomada pela essência maníaca ou que haja continuidade e repetição dela ao longo do tempo.

Gostaríamos de ressaltar que, devido ao forte papel exercido pela relação interpessoal na investigação psicopatológica fenomenológica, existe uma considerável sobreposição entre os procedimentos metodológicos e os terapêuticos. De certo modo, toda terapêutica é uma investigação interpessoal e toda investigação toma as cores de um investimento psicoterápico. Do mesmo modo, embora passemos a seguir a identificar as fases do procedimento diagnóstico fenomenológico, vale registrar que estas fases se sobrepõem e se imbricam, de modo que a realização de uma sempre traz em si algo da realização de outra. Toda produção do método é perpassada por relações dialéticas. Rigorosamente, o que descreveremos a seguir são as habilidades básicas que um psicopatologista dialético-essencialista deve possuir para realizar sua atividade.

\section{As etapas do diagnóstico fenomenológico dialético-essencialista}

A seguir, proporemos uma metodologia diagnóstica dividida em cinco etapas. As etapas seguem a cronologia habitual de uma entrevista diagnóstica ou de um atendimento psiquiátrico ou psicoterápico. Há uma sobreposição mais pronunciada delas no seguimento longitudinal dos casos, quando já existe um conhecimento mais aprofundado do paciente, por parte do psicopatologista. Nesses momentos, há uma tendência à restrição da fase 1 a seus aspectos fundamentais e a uma maior concentração dos esforços na fase 5 .

\subsection{Relato do sujeito e descrição psicopatológica}

O ponto zero da procura por uma opinião de um psicopatologista é a experiência de uma pessoa, ou de um familiar, de uma situação psicológica ou comportamental com a qual a própria pessoa ou familiar não se sentem habilitados para lidar. Essa situação 
original dá início a um relato, que deve ser ouvido com atenção pelo psicopatologista. Estando frente a frente com um semelhante que nos procura ou nos é trazido devido a alguma experiência que não consegue tolerar ou processar, nosso passo inicial é iniciarmos uma entrevista psicológica aberta (VAN PRAAG, 1992; STANGHELLINI; MANCINI, 2017) ${ }^{5}$. A característica da entrevista aberta é justamente sua preocupação com a não predeterminação de qualquer tema. Psicopatologista e paciente iniciam uma conversa - geralmente conduzida pelo primeiro, mas não necessariamente - que se deixa avançar gradualmente por caminhos que não podem ser previstos, embora normalmente se guie por uma mínima investigação acerca das vivências que levam o paciente a solicitar ajuda. Lá e cá o psicopatologista deve intervir, solicitando o detalhamento de alguma vivência ou inquirindo algum ponto que a fala espontânea do paciente não valorizou e que o psicopatologista pressente ser de valor diagnóstico. Finlay (2008) aproximou, em uma feliz metáfora, este procedimento aos movimentos do tango, no qual os dançarinos improvisam passos, experimentando diversas mudanças de ritmo. A narratividade é elemento fundamental para o início do acesso ao psiquismo e à experiência vivenciada pelo outro (ROVALETTI, 2003; SERPA JR, 2014), A forma como a narratividade se articula já deve ser mérito de atenção do psicopatologista, lado a lado com seu conteúdo. Embora se espere de uma queixa de um paciente (ou familiar) uma narrativa mais ou menos concatenada dos fatos que o levaram à consulta (ou, no caso de um seguimento, dos temas a ser tratados na ocasião específica), não é sempre que isso ocorre, no caso das entrevistas abertas. E a insuficiência de direcionalidade do discurso é carregada de significado para o psicopatologista, em mais de um nível. Em condições não psicóticas, uma fraca direcionalidade do discurso espontâneo pode indicar, por exemplo, uma dificuldade do paciente em enfrentar seus próprios temas, como costuma acontecer com personalidades fóbicas. Por outro lado, a narrativa do paciente pode trazer temas de grande dramaticidade que, no entanto, já não tem relevância afetiva para o paciente naquele momento de sua vida. Exemplo disso são pessoas histéricas que, muitas vezes, começam a primeira entrevista contando sobre violências que sofreram ao longo da vida. Essas violências, genuínas e merecedoras de respeito e atenção, podem, contudo, exercer

\footnotetext{
${ }^{5}$ Embora se possa também defender uma entrevista semi-estruturada como o padrão ouro da psicopatologia (NORDGAARD; SASS; PARNAS, 2013) há, entre as duas formas de entrevista, um ponto em comum, a disponibilidade do pesquisador em ouvir aquilo que a experiência em primeira pessoa do paciente julga mais relevante. A forma fenomenológica semi-estruturada serve como um guia para a prosa do paciente e, deste modo, pode ser vista como uma abordagem inicial a ser estendida pela forma aberta de entrevista (SASS et al., 2017).
} 
somente uma função de colorir a relação paciente-psicopatologista, trazendo tons fortes para a cena diagnóstica. Por vezes, a queixa que motiva a procura do paciente nada tem a ver com esses fatos passados. Em um nível mais grave, o relato subjetivo espontâneo de esquizofrênicos é marcado pela incapacidade total de se estruturar em um discurso lógico, oferecendo, já de largada, importantes elementos para a construção do ato diagnóstico.

O psicopatologista experiente sabe que, concomitantemente ao relato do paciente, deve prestar muita atenção aos sinais corporais que acompanham o relato, o movimento de olhos, a tonalidade de voz, o fluxo do discurso, a posição na cadeira, os trajes e a marcha do paciente. É necessário que o psicopatologista se indague se todas essas manifestações, ainda do ponto de vista da análise da experiência subjetiva, estão em harmonia com o relato que ouve. A dissonância entre o relato e as manifestações concorrentes já fornecem indícios de alguma pista diagnóstica. Por exemplo, o relato de uma ansiedade muito grande, acompanhada de receio de perda de controle da própria mente; ou o temor de que o mundo esteja perdendo seus perfis habituais, podem fazer parte de experiências integrais muito distintas entre si. Um paciente ansioso fóbico fará esse relato acompanhado de uma visível tensão no rosto, tocando no assunto de modo atabalhoado, como se a própria menção ao tema já acarretaria algum fato pavoroso. Seu corpo pode apresentar sudorese, suas mãos, inquietude e o modo de olhar, avidez por proteção. Por outro lado, o mesmo relato, composto por palavras idênticas, pode nascer de uma experiência diferente, digamos, esquizofrênica. Nela, o paciente se apresentará mais distante ao contato, mais voltado a si mesmo e menos ao psicopatologista. Procurará antes extrair do psicopatologista alguma explicação para o que está vivendo do que procurará proteção. Seu olhar pode ser mais perdido, suas vestimentas mais descuidadas ou até exóticas, concedendo ao exame psicopatológico uma atmosfera geral totalmente diferente daquela constatada no contato com o ansioso fóbico.

Com isso, já podemos ver que o relato do sujeito, ou seja, a simples escuta da experiência em primeira pessoa (JASPERS, 1997), não pode ser o objetivo último da investigação psicopatológica, mesmo que esta ainda seja entendida como um colocar-se no lugar do outro, no sentido original que Jaspers dá à empatia (Einfühlen) (JASPERS, 1968; 1997). O colocar-se no lugar do outro é, a nosso ver, acima de tudo um movimento de aproximação com o outro, de interesse antropológico-epistêmico, e ainda, uma forma de compaixão, originária do terreno da ética. Embora seja muito importante, não abraça toda a complexidade da compreensão do modo de existir no mundo (GALLAGHER; ZAHAVI, 2013). No ato de empatia jaspersiano, o examinador deve, metodologicamente, 
afastar-se demais de si mesmo, com vistas a penetrar no outro, para representá-lo (SPIEGELBERG, 1964; BLANKENBURG, 1980; FUKUDA; TAMELINI, 2016). De certo modo, este despojamento da atenção sobre si mesmo para centrar-se na atenção sobre o outro não é mais do que um primeiro passo do procedimento fenomenológico, que, como já apontava Binswanger, não pode se limitar a uma "[...] fenomenologia descritiva das "manifestações subjetivas da vida psíquica" [...]" (BINSWANGER, 1960, p.9-10). Um procedimento fenomenológico integral necessita de um balanço mais equânime da relação observador-observado.

A subjetividade do relato não deve fazer dela um objeto científico de menor validade. Não apenas porque a experiência em primeira pessoa é, em última análise, aquilo que faz com que o psicopatologista seja acionado e sua razão de existir. Do ponto de vista científico, como observaram argutamente Leal e Serpa (2013, p.2943), “[...] subjetivo não é idêntico a privado. É necessariamente aberto à validação intersubjetiva". A subjetividade do relato ganha, portanto, validade científica na medida em que suas imbricações com a interpessoalidade vão sendo reveladas. É este movimento de aprofundamento na realidade do objeto psicopatológico que apresentaremos a seguir.

\subsection{O exame da ressonância afetiva}

O exame da ressonância afetiva (RA) é a segunda matéria-prima da qual se faz o diagnóstico psicopatológico, atuando em consórcio com a primeira etapa. A RA, sob os diversos nomes que recebeu ao longo da trajetória do pensamento fenomenológico, sempre recebeu status de condição fundamental da existência. Perfila-se aqui a Befindlichkeit de Heidegger (2001) na filosofia; o diagnóstico por penetração de Minkowski (1973), a sintonia de Bleuler (2011), o existencial feeling, de Ratcliffe (2008), diagnóstico atmosférico de Tellenbach (1975), diagnóstico "por sentimento" de Binswanger (1977) e a própria contribuição de um dos autores sobre a função primária da RA na psicopatologia (MESSAS, 2004; 2010). Por RA devemos entender um fenômeno interpessoal que não gratuitamente retira sua origem metafórica da música. $\mathrm{Na}$ música, o fator determinante da recepção e apreciação, pela consciência do ouvinte, da beleza da arte musical é um fenômeno sonoro, quase tátil, de ressonância. A sonoridade da música quase toca o ouvinte, abraçando-o de modo a unificar-se com ele. Na música, ouvinte e obra unificam-se, harmonizando-se em uma só frequência. Nela, há uma penetração da sonoridade nos interstícios da própria consciência do ouvinte, 
transformando a sonoridade em parte integrante da sua existência. Essa unificação por harmonia $^{6}$ está no fundamento do processo de realização de reconhecimento psicopatológico. Sua evidência no contato clínico é banal. Se nos deixamos levar por uma entrevista com um paciente depressivo, ao longo dos minutos ou das horas, somos arrastados para nos igualarmos com o peso e a sobriedade de sua experiência pré-reflexiva de mundo. Todo o seu ser depressivo "vibra em uníssono", para utilizarmos as clássicas palavras de Minkowski, conosco, convocando um sentimento depressivo do qual fazemos parte, de modos diversos, nós e o paciente. Exemplo dessa diversidade: o paciente experimenta sua melancolia como incapacidade de enxergar algum futuro para sua vida, que sente cerrada pelas garras de um dever que não consegue cumprir e do qual não consegue se livrar. Simultaneamente, o psicopatologista sente um desânimo, um aborrecimento ou um peso na execução de seu dever de médico ou psicólogo, um sentimento vago de que será muito árdua sua tarefa de restituir sentido para a vida daquele semelhante do qual está tratando. Vale dizer, embora possa parecer óbvio, que não é necessário que nos tomemos integralmente pela experiência depressiva para sermos capazes de ressoar com ela.

A RA é, portanto, um fenômeno originário eminentemente de constituição interpessoal do mundo (HUSSERL, 2004) - ou coconstituição da existência e, consequentemente, um fenômeno dual ${ }^{7}$, a partir da qual emerge uma forma essencial. Assim, o método fenomenológico orienta-se por uma epistemologia de segunda pessoa, sustentada na ideia de que as vivências que emergem em uma relação pessoal e íntima são o estofo de um conhecimento psicopatológico seguro (STANGHELLINI, 2007). No entanto, pensamos que esta epistemologia de segunda pessoa seja mais bem representada por uma ontologia da interseção das duas pessoas em contato: da observação dos

\footnotetext{
${ }^{6}$ No sentido em que utilizo aqui, a unificação também pode ser denominada simpatia, em sua acepção mais castiça, qual seja, de experimentar o mesmo pathos, a mesma experiência, do que o outro. No que se refere ao termo empatia, temos preferido não utilizá-lo como conceito técnico, pois são muitos os seus significados (RATCLIFFE, 2017), o que distorce a precisão de sua significação. No mais das vezes, a empatia conglomera diversas experiências de encontro, que contêm mas de modo algum se limitam à noção jaspersiana de "colocar-se no lugar do outro". Este colocar-se no lugar do outro, do ponto de vista da metodologia fenomenológica psicopatológica, só pode ser atingido, em um procedimento metodológico, e ainda assim de modo necessariamente parcial, como compreensão transcendental - v. seção 5 . A colocação no lugar do outro, por meio de um exercício imaginário, só pode ser aceita tecnicamente se cumprir os requisitos integrais de um proceder metódico. Se não, se trata de um ato compassivo, importante e desejável, mas grosseiro demais para ser tomado como parte de um diagnóstico científico. Mais adequada me parece a definição de Scheler (1954) sobre a empatia: um movimento de aproximação do outro (GALLAGHER; ZAHAVI, 2013).

${ }^{7}$ É verdade, que essa dualidade mediada por um "inter" quase independente, como veremos a seguir, pode se dar também em uma relação grupal. A original obra de Di Petta, com sua Daseinanalyse de grupo em drogadicção, é um exemplo vibrante dessa possibilidade (DI PETTA, 2006).
} 
movimentos, parcialmente espontâneos e parcialmente conduzidos pelo examinador, nos quais se desenrola a RA e surge esta intersecção fundamental, nasce o próximo passo metodológico, que examinaremos a seguir.

\subsection{A produção da terceiridade dual ${ }^{8}$}

Nessa terceira etapa do procedimento diagnóstico fenomenológico, dois passos são realizados quase que simultaneamente. Embora sejam condições distintas, a produção da terceiridade dual (TD) e o passo seguinte, a intuição eidética (IE), ocorrem de tal modo vinculadas entre si, em um procedimento diagnóstico ou terapêutico, que sua divisão em duas etapas aparentemente não se justificaria. A separação entre as duas, no entanto, é importante para que o psicopatologista tenha consciência de que esteja realizando dois movimentos diferentes e, por isso, a manteremos aqui. A IE é um processamento imediatamente posterior à produção da TD. Poderíamos dizer que a produção da TD é um constituinte inevitável da habitualidade da vida, ao passo que a IE deriva de um anseio epistemofílico específico e antropologicamente sofisticado. Vejamos como se produz espontaneamente a emergência essencial desta terceiridade.

Toda relação, como vimos, produz uma RA. Essa RA ocorre sobre uma porção específica da dualidade envolvida (ou das dualidades, no caso de um grupo), ou seja, apenas algumas das vivências atuais nas duas consciências em diálogo entram em ressonância. As porções das consciências relacionadas que entram em ressonância geram o que chamamos de essência interpessoal. Essa essência interpessoal constitui-se, por assim, dizer, em um terceiro dual, pois não é única e exclusivamente nem a subjetividade do paciente, nem a do psicopatologista. Não podemos nos perder no aparente paradoxo da noção de terceiro dual. A dualidade, ao constituir-se, amalgama algumas partes componentes de cada experiência de forma a estabelecer essa terceiridade essencial que denominamos TD. Essa terceiridade não pode ser separada das partes constituintes da relação, entretanto, só existe na vigência de sua presença ressonante. E será ela o elemento decisivo para a eficácia do ato diagnóstico, como ficará mais claro com o decorrer da

\footnotetext{
${ }^{8}$ A noção de terceiridade dual não se confunde com a de conhecimento de terceira pessoa, característica do conhecimento psicopatológico neo-positivista (TAMELINI; MESSAS, 2017). O conhecimento de terceira pessoa constitui um modo de saber compartilhável por uma comunidade. A terceiridade dual é uma redução fenomenológica do conhecimento de segunda pessoa, ou seja, é um refinamento deste conhecimento íntimo que se dá na dualidade e que, apenas com dificuldades, assume o estatuto coletivo do conhecimento de terceira pessoa.
} 
apresentação desses passos metodológicos. Mantendo o exemplo que usamos acima, a melancolia, só é atingível, na realidade vivida, por meio de ima TD. Porém, ainda que esse fenômeno terciário não possa ser decomposto em suas duas partes unitárias - a saber, o paciente e o psicopatologista -, sua observação empírica válida só é possível pelo exame simultâneo do modo como ele se manifesta fenomenicamente nas duas existências em colóquio. Há, assim uma coexperiência, uma projeção da subjetividade do paciente na do observador, que faz com que, de certo modo, ler a si mesmo seja equivalente a ler a essência de algo que ocorre no outro, fenômeno que Calvi denominou de "prassi mimética" (CALVI, 2009). Ballerini soube descrever com maestria essa sinergia de vivências, indispensável para as ambições científicas de uma psicopatologia fenomenológica: “Qualquer que seja nossa aproximação terapêutica, devemos nos deixar guiar pela atenção e pelo estudo da experiência interna do paciente e de nossa ressonância com ela: ou seja, observando a subjetividade do outro enquanto se observa a própria" (BALLERINI, 2004, p.35). A mesma trilha é partilhada por Binswanger, ao afirmar que: "o (investigador) se observa a si mesmo durante o ato de perceber" (2007, p.300) e por Rümke (1990), com sua noção de "sentimento precoce", que novamente vem sendo empregado pela psicopatologia (GRUBE, 2006; GOZÉ; NAUDIN, 2017).

É do produto emergente da simultaneidade de duas subjetividades em contato que aparece o objeto fenomenológico essencial, emergindo em uma TD, cujas estratégias de tratamento técnico serão vistas na próxima seção. Antes, gostaríamos de nos valer de um exemplo para melhor esclarecimento do leitor. São exemplos simples, que todo clínico já experimentou em sua atividade profissional. O primeiro deles: o paciente tipicamente histérico, no decorrer do seu relato como sujeito, durante o esforço que nos leva a procurar conhecer suas experiências em detalhes, vai, gradual e imperceptivelmente, transformando-nos, como psicopatologistas, em pessoa muito poderosa. Não se trata aqui de mera sedução. No mais das vezes, trata-se apenas de um modo atmosférico de conduta (TELLENBACH, 1981; SASS; PIENKOS, 2013; COSTA et al., 2014), no qual o psicopatologista nem mesmo sabe como chegou ao estado subjetivo que atingiu. Nesse estado final, sente-se forte, dotado de poderes para resolver o problema do paciente, seguro de si mesmo e não raramente assume um papel paternal diante do paciente. Essa construção simultânea de um sujeito relatando fraqueza enquanto o outro se transforma imperceptivelmente em polo forte e dirigente da situação é típica de uma terceiridade dual histérica (MESSAS; ZORZANELLI; TAMELINI, no prelo). A terceiridade está na simultaneidade de um sujeito experimentando insegurança e o outro, força e segurança 
(isso para ficarmos apenas no aspecto sentimental da terceiridade, já que ela compreende também outros aspectos, como representações, expressões corporais, funções cognitivas ou executivas, etc; enfim, uma formação integral da existência). A TD típica histérica deve ser diferenciada, por exemplo, daquela que ocorre na presença de uma pessoa esquizofrênica. Façamos um experimento mental, no qual todo o relato experiencial do paciente fosse idêntico ao histérico acima, mas estaria ocorrendo em um paciente iniciando um quadro psicótico e relatando suas experiências desagradáveis apenas como um sentimento de ansiedade e medo extremos. No transcurso da entrevista, à medida que o psicopatologista se permite entrar em RA com o paciente, seus estados mentais provamse ser diferentes daqueles experimentados junto ao histérico. Sente-se tomado por uma atitude indagativa sobre o estado subjetivo vivenciado pelo paciente, tem dificuldades em encaixá-lo nas suas próprias experiências, esbarra com um hiato entre aquilo que está acostumado a viver em suas relações cotidianas e aquilo que a ressonância com o outro provoca. Procura representar para si mesmo como podem ser as vivências alteradas do outro, já que não as encontra em seu próprio íntimo; enfim, há um desconforto que o coloca no papel de um investigador de fronteiras inexploráveis da vida humana, às quais se concede o nome de psicose. A experiência psicótica só pode ser cientificamente acessada se encontrar RA no psicopatologista e consolidar-se em uma TD específica, na qual o estranhamento é a manifestação principal. Kimura identificava o transtorno esquizofrênico a uma alteração da aida, da atmosfera do "inter" que ocorre nas relações humanas (KIMURA, 2000). Esse “inter" é o local existencial no qual ocorre a TD. Vale reiterar que quando duas pessoas entram em ressonância, não o fazem com todas as partes de sua pessoa, mas apenas com algumas delas, aquelas que dependem das condições do encontro. É peculiar aos quadros psicopatológicos graves que a patologia colore toda a terceiridade; por outro lado, em quadros leves, nos quais grandes setores da existência estão preservados, a TD pode não revelar o centro da queixa, fazendo com que mais de uma perspectiva sobre a mesma experiência patológica seja possível (MESSAS; TAMELINI, prelo). Por exemplo, podemos atender a um paciente deprimido sem que a RA e a subsequente TD tenha uma dominância depressiva.

As TDs são, ontologicamente, um dos principais modos de sustentação da existência no mundo. Parte relevante de nossa sustentação existencial se dá, principalmente, pela força com que as TDs cimentam a estrutura da existência no outro, configurando a chamada coconstituição da existência. As TDs são mais uma prova de que o eu se constitui como participante substancial do outro. Um exemplo claro disso são 
algumas relações pessoais desgastadas, nas quais parece não mais haver nenhum vínculo que não sejam as reprovações mútuas. Embora, subjetivamente, essas reprovações sejam incômodas e indesejáveis, estruturalmente, a força de colagem das consciências individuais em cada TD é tal que impede que se desfaça o laço. $\mathrm{O}$ abandono do laço equivaleria à perda de apoio no mundo e a um abandono ontológico profundo, que é menos tolerável do que o desgaste consolidado. É importante que não se confunda a perda da capacidade de produção de TD com a perda do outro na relação. A TD, ou seja, o modo como certa parte da consciência vibra com a de outrem, é mais importante para o eu, às vezes, do que a própria personalidade singular desse outrem. É por isso também que, frequentemente, trocando-se de relações, retornam as mesmas formas relacionais: a consciência parece estar acostumada com um gênero de TD e essa TD acaba por determinar o papel que o novo outro terá na nova relação. Nos casos clínicos em que finalmente um dos membros da relação consegue se libertar dessa compulsão à repetição, no sentido de Freud, geralmente já há uma nova edificação interpessoal amadurecida há muito tempo, com a habituação da consciência de um dos sujeitos com uma nova forma de TD. A TD é uma condição antropológica geral: toda relação interpessoal, involuntariamente, leva à emergência de uma experiência mútua das partes envolvidas. Dessa condição antropológica geral a psicopatologia extrai sua capacidade diagnóstica. Portanto, em tese, o ato diagnóstico fenomenológico está ao alcance de toda e qualquer pessoa que esteja atenta aos produtos psicológicos das terceiridade nas quais se envolve. A diferença do psicopatologista em relação ao leigo está no apuro de sua capacidade de identificar essas terceiridades; esse apuro vem do treinamento e da experiência clínica. Não se pode, contudo, excluir que, como em todas as atividades humanas, haja indivíduos naturalmente mais dotados para a execução desta prática.

A TD emerge de uma atividade passiva do observador, denominada passividade ativa programática. $\mathrm{O}$ psicopatologista deve se manter em uma atitude contemplativa, no sentido de Tellenbach (1975), conduta que "convoca" a manifestação da terceiridade, em vez de extraí-la como sob um interrogatório. Essa atitude ativamente contemplativa deve ser mantida até que surjam aos poucos, em sua consciência, de forma amadurecida, as visões essenciais de TDs, sobre as quais o psicopatologista deve se debruçar para testar suas hipóteses diagnósticas. Não infrequentemente, o diagnóstico fenomenológico se deixa revelar mesmo sem o exaustivo inventário dos estados subjetivos do paciente ou da avaliação objetiva de suas ditas funções mentais ou cognitivas. O psicopatologista é, pois, apenas parcialmente ativo em suas intervenções realizadas durante o relato subjetivo do 
paciente, guiando-o por algumas vias que sua experiência indica ser mais frutíferas para a emergência da TD. Entretanto, o fator mais relevante para a produção da terceiridade é sua própria força imanente, involuntária, de modo que a principal habilidade exigida do psicopatologista seja a paciência (TATOSSIAN, 2006). Essa TD essencial surge como fruto de um movimento espontâneo, cuja fonte primeira independe das vontades de paciente e psicopatologista. Há algo que surge no contato, um terceiro termo (TELLENBACH, 1992) que vai além das possibilidades de controle das partes. É evidente que uma entrevista psicopatológica ou um atendimento psiquiátrico ou psicológico não ocorrem se não houver atos voluntários de cada pessoa envolvida na relação. Por movimento espontâneo aqui queremos indicar que a propulsão dual que acaba por constituir, via RA, a TD, ocorre independentemente da vontade dos parceiros da relação. Enquanto o paciente nos apresenta os motivos de suas queixas e nós as ouvimos, ambos os atos de caráter voluntário, ocorre um movimento de sintonia subterrânea, uma afinação interpessoal da qual não conseguimos nos desligar e que não somos capazes de controlar. Essa afinação é, ontologicamente, mais importante em termos de validade científica do que propriamente os atos voluntários e, portanto, é mais válida também (GABBANI; STANGHELLINI, 2008; MESSAS; FULFORD; STANGHELLINI, 2017).

A importância diagnóstica da produção da TD aparece com maior clareza nas situações em que há uma discrepância entre os relatos do sujeito e a RA. Imaginemos um caso, visto pela primeira vez pelo psicopatologista, no qual a família do paciente queixase de que ele/ela seja mentiroso. Ora, nessa situação, o psicopatologista depara-se com um dilema: ou acredita no paciente, correndo o risco de se deixar engabelar por mentiras que o desviam dos objetivos terapêuticos, ou desacredita, comprometendo severamente a relação terapêutica. Nesse caso, os relatos dos sujeitos parecem ser pouco fiáveis como fundamento de validade. É nessa hora que se vê a importância capital da emergência da TD. Será o exame da terceiridade que emerge da relação que autorizará ou não as conjecturas diagnósticas preliminares do caso. Seguindo no exemplo, pode-se imaginar que, ao longo de seu relato, o paciente narre fatos que pareçam algo fantasiosos e irreais, contados de modo a chocar o psicopatologista. A eventual mentira relatada subjetivamente emerge em uma essência na qual seu ponto mais destacado é, por parte do paciente, a procura de atenção do psicopatologista; por parte deste, um sentimento de que o paciente exagera ou dramatiza seu sofrimento. Um sofrimento intenso com cores de falsidade - por parte do paciente, sintonizado com o sentimento de estar sendo 
mobilizado com superficialidade - por parte do psicopatologista - seria a descrição essencial da TD obtida. No caso, estamos mais próximos do fenômeno essencial histérico há pouco mencionado (que só pode se confirmar, evidentemente, depois de um conhecimento mais preciso e longitudinal do paciente). Diversamente, se a mentira emerge essencialmente como uma irresponsabilidade com as palavras e com a profundidade da comunicação, a TD que se manifestará será outra. Imaginemos um quadro de hipomania eufórica. Subjetivamente, o paciente sente-se confortável com seu relato, indiferente àquilo que o psicopatologista possa pensar dele. Está alegre, agitado, preenchido integralmente por seu tema. O psicopatologista, por sua vez, sente que a atmosfera sentimental na relação é contagiante, mesmo que os relatos sejam nitidamente inverídicos. Essa simultaneidade de uma indiferença em relação à verdade dos relatos combinada com uma RA prazerosa para os dois lados, é típico de algumas hipomanias eufóricas.

As TDs são proporcionais e eventualmente transitórias, ainda que essa transitoriedade possa levar muito tempo para ocorrer (toda uma etapa de uma vida, por exemplo, pode ser dominada por uma forma predominante de TD). Como ilustração de sua proporcionalidade, podemos imaginar uma pessoa marcadamente obsessiva em sua vida afetiva que, no campo profissional, não apresente nenhuma característica obsessiva. Como exemplo de transitoriedade, lembremos que uma pessoa hipertímica pode, no decorrer de sua vida, amadurecer e passar a não constituir mais TDs de natureza hipertímica, ou constituí-las de modo leve, inócuo ao desenvolvimento de suas potencialidades psicológicas. Da proporcionalidade e da transitoriedade das TDs dependerá, como veremos mais adiante, a compreensão do sentido existencial das essências patológicas. Também a terapêutica, em sua vertente psicológica, apoia-se na proporcionalidade e transitoriedade das TDs.

Igualmente importante é reconhecer que as TDs se alternam e se sucedem. Uma pessoa melancólica pode, por exemplo, em um período de muita necessidade de apoio, abonar-se em uma TD histérica, embora essa forma de terceiridade se dissolverá assim que a situação patológica se dissipar. Essa propriedade das TDs justifica o porquê de um observador decidir-se, em um momento, por certo diagnóstico e, em outro momento, por um segundo diagnóstico (BACA-GARCIA et al., 2007). Também a variabilidade diagnóstica interexaminadores (HELZER et al., 1977; PETHÕ et al., 2007) depende em parte, do fato das TDs se sucederem e se dissolverem. 


\subsection{Intuição eidética (IE) e redução fenomenológica (RF)}

Dissemos acima que TD e IE caminham ombro a ombro. Até aqui, enfatizamos as características da terceiridade. Ela tem como atributo fundamental o estilo de ligação entre a subjetividade do paciente e aquela do psicopatologista, constituindo uma entidade ontológica de pleno direito. Agora, nossa ênfase recai sobre os esforços que o psicopatologista tem de fazer para conseguir acessar, como cientista humano, a TD da qual subjetivamente faz parte e, por meio dela, a existência que examina. Para assumir seu papel de cientista empírico, ele deverá realizar uma tentativa de separação da união antropológica estabelecida até então com o paciente, para destacar sua consciência subjetiva do conjunto antropológico no qual está imersa, por meio de um exercício afetivo-cognitivo denominado redução fenomenológica (RF). Este exercício abre caminho para que, um ato cognitivo denominado intuição eidética (IE), possa finalmente identificar a essência da terceiridade à qual pertence. O psicopatologista, nesse estágio, deve ir além da ligação de si mesmo com o outro, para, com isso, poder começar a dirigirse ao outro em outro nível investigativo ${ }^{9}$. O dirigir-se ao outro que se inicia agora já vem carregado dos passos anteriores que permitem a atestação da realidade fundamental da inserção do paciente no mundo e, por isso, está mais protegido das limitações de uma compreensão do outro demasiadamente imaginária. Esse movimento conclui-se no momento em que o psicopatologista identifica a essência da experiência transtornada de seu paciente. É importante enfatizar que, como já nos previne Merleau-Ponty (2011), essa saída de si, sobre a qual falaremos a seguir, é necessariamente incompleta, pois a condição de um conhecimento efetuado pela razão do psicopatologista jamais atinge um grau de pureza absoluta; não é possível uma retirada absoluta do contexto em que se está imerso. Esse ato de saída de si mesmo será sempre ambíguo e parcial, embora essa parcialidade seja o mais claro acesso à existência do outro no mundo.

A IE é o centro de maior evidência do procedimento diagnóstico em psicopatologia fenomenológica ${ }^{10}$. Como já vimos acima, o procedimento diagnóstico assenta-se sobre a expressão da experiência subjetiva do paciente em ressonância com a do psicopatologista, produzindo uma TD. Nesta seção, gostaríamos de examinar com

\footnotetext{
${ }^{9}$ Observe-se aqui como este "dirigir-se ao outro" difere do procedimento jaspersiano empático há pouco indicado (seção relato do sujeito e descrição psicopatológica).

${ }^{10}$ Vale lembrar aqui que o exercício da IE em psicopatologia, assim como seu sentido, é diferente daquele executado na filosofia fenomenológica (BLANKENBURG, 2013).
} 
mais atenção esse procedimento, que leva à identificação do "entre" interpessoal e ao reconhecimento da essência patológica vivida pelo paciente. Para que o eu do psicopatologista seja capaz de realizar intuições eidéticas, deve se aproveitar, em primeiro lugar, de um atributo próprio dos fenômenos terceiros duais. Esse atributo é a face oposta daquele que acima vimos, onde destacamos a proporcionalidade e a transitoriedade da TD. A saber.

A TD deve ser suficientemente estável para que o eu do examinador possa ser capaz de reconhecê-la em uma IE. Assim, a experiência de uma pessoa com mania eufórica, por exemplo, requer, para sua identificação essencial, um intervalo de tempo no qual paciente e psicopatologista permaneçam em contato direto para que este possa realizar a passividade ativa programática. Imaginemos um paciente cuja mania se caracterize pelo excessivo espírito jocoso. A primeira manifestação da TD será a contaminação do psicopatologista pelo riso que o paciente provoca. Não é raro que sejamos tomados por um acesso de riso frente a alguma observação espirituosa de um paciente em mania, mesmo se essa observação esteja fora do contexto em que apareça. Nesse caso, ambos, paciente e psicopatologista, estarão sintonizados. Com o decorrer do tempo, essa jocosidade ressonante passa a produzir, no psicopatologista, a impressão de superficialidade e, com isso, do riso em conjunto dividido com o paciente, o psicopatologista passa a se dominar pelo enfado. Agora, há uma dissonância na produção da TD. Essas duas etapas diferentes da relação, compostas por duas TDs diferentes, uma vez examinadas pelo psicopatologista, podem ser reunidas em uma única TD, a essência da experiência dual, que é captada por uma IE. Essa intuição unifica a aparente diferença entre a sintonia com a jocosidade e, em seguida, com o enfado. Há entre ambas uma semelhança, contida na superficialidade do afeto que preenche a cena: o psicopatologista rememora que os seus risos se faziam sobre temas triviais que, com o passar do tempo, mostram que nada são senão banalidades descomprometidas com a seriedade do encontro terapêutico. Essa unificação de distintas TDs possui uma essência, eideticamente acessada, que pode ser assim definida: uma relação superficial, incapaz de se voltar a temas de maior relevância, escorregando no verniz dos acontecimentos. Na consciência do paciente, isso recebe o selo da euforia e da jocosidade; na do psicopatologista, da pouca sustentação da atratividade existencial do paciente. Ora, para que ocorra essa síntese de duas TDs em uma IE, que unifica as diferenças das terceiridades, é necessário que haja a permanência do estado maníaco por um intervalo de tempo suficiente para que seja reconhecível eideticamente pela cognição do psicopatologista. Uma estabilidade mínima 
da presença maníaca é imprescindível para a IE das TDs. A IE necessita, portanto, de um tempo de gestação e amadurece em um momento exato e ideal da relação, no qual surge o conhecimento psicopatológico. Alguns casos clínicos, nos quais os fenômenos patológicos são demasiadamente transitórios, podem dificultar a realização de uma IE. Um exemplo disso são os pacientes bipolares de ciclagem rápida, que realizam TDs diferentes, de acordo com a hora do dia em que são atendidos.

A construção de múltiplas TDs dificulta a IE da essência em questão. $O$ psicopatologista fenomenológico deve ter sempre em mente as limitações na capacidade de identificação de essências patológicas. Ele deve ter consciência de que o conhecimento que atinge é instável, por vezes caótico e que, embora seja objetivo, expressa uma objetividade fugidia e muitas vezes incerta. Talvez seja exagerado afirmar que o psicopatologista fenomenológico seja um anárquico epistemológico (DI PETTA, 2012, p.262), no entanto, com certeza, o que possui de melhor é a modéstia de dobrar-se aos limites que o conhecimento sobre o humano impõe. E que, curiosamente, aumentam na medida da sua inserção na relação com o outro, nas TDs de que participa e dos atos de IE que executa. O psicopatologista fenomenológico, estudioso da alma humana, sabe que quanto mais se aproxima de seu objeto, mais ele se distancia. O conhecimento do humano é assim: só é crível e válido se não se distanciar em demasia da ligação umbilical com o mundo; mas, pelo fato de proceder dessa proximidade íntima com as coisas, não consegue o conforto seguro que apenas as abstrações podem oferecer.

\subsection{Dinâmica da Intuição Eidética: a Redução Fenomenológica}

A IE é um daqueles exercícios básicos que são mais fáceis de realizar do que de definir (FERNANDEZ, 2017). Parece-nos mais em harmonia com a própria natureza da IE apresentar o modus operandi que a possibilita e deixar que, gradualmente, o leitor se aproprie de seu significado. Neste ponto da aplicação do método, a passividade ativa programática substitui-se por uma nítida atividade intelectual do psicopatologista. A esse esforço de supressão da realidade imediata de suas experiências para a descoberta dos seus fundamentos existenciais, dá-se o nome de redução fenomenológica (RF) ${ }^{11}$. A RF é

\footnotetext{
11 Também a redução fenomenológica na psicopatologia fenomenológica é diferente daquela da filosofia. Di Petta propõe que ela (epokhé, em suas palavras) na psicopatologia é "...mais afetiva que cognitiva...", (DI PETTA, 2012, p. 245). Para nossos propósitos clínicos, trataremos de modo indistinto a epokhé e a redução fenomenológica, como o fazem alguns psicopatologista (DI PETTA, 2012; Naudin, 2003, v. nota
} 
uma espécie de polimento experimental e metódico da experiência de mundo, visando à preparação da cognição do psicopatologista para a visão da essência do fenômeno patológico vivido pelo paciente a partir de um ato de intuição. Essa intuição não deve ser confundida com um ato intelectual puro de uma consciência desencarnada. Pelo contrário, a IE na psicopatologia radica na possibilidade do sujeito investigador de conhecer diretamente, por meio de seu corpo, suas sensações, sentimentos e intelecto, o aspecto invariável e generalizável da experiência do outro (BINSWANGER, 1977, p.80). A RF prepara uma passagem do nível experiencial antropológico ao nível ontológico original, no qual o mundo é coconstituído. Com este procedimento, o sujeito do conhecimento paradoxalmente isola-se do mundo pare melhor aliar-se a ele (MERLEAU-PONTY, 1968). É um ato, em primeiro lugar, de distanciar-se de si mesmo, eximindo-se de sua realidade no mundo, em seu corpo e na relação com o outro. Seu exercício é penoso e difícil, pois se trata de um afastamento radical, que inclui a sua própria presença no mundo ${ }^{12}$.

Essa saída metodológica de si mesmo, para reencontrar o mundo em uma profundidade não dada pela atitude passiva obtida por meio da RA, é um ato antropológico de despersonalização e mesmo de desrealização (DE MONTICELLI, 1996), que atinge também a relação paciente-psicopatologista (DI PETTA, 2012). Esse descolamento metodológico, fundado na capacidade humana de recusar parcialmente a realidade, é o único instrumento capaz de fazer com que o real possa retornar em um passo seguinte como doação originária de um sentido implicado em toda a existência. Essa doação originária de um sentido nuclear e típico que permeia as experiências psicopatológicas é captada pela IE. A RF, portanto, agindo sobre a TD, prepara a IE, num processo metabólico contínuo e imbricado, como momentos de uma reação enzimática. Vejamos um exemplo. Imaginemos que um paciente esteja muito agressivo conosco, ofendendo-nos em um ponto sensível. Nossa primeira reação é sentirmos raiva desse paciente. Essa nossa raiva é genuína e justificável. Ela está em nós e nos invade. Nossa reação normal a essa vivência é repudiar o paciente ou atacá-lo de volta, insultando-o em

10 abaixo), embora tenhamos franca consciência da alteração que isto comporta no método original husserliano (GALLAGHER; ZAHAVI, 2013) e em sua aplicação rigorosa na psicologia (GIORGI, 2009). ${ }^{12}$ A semelhança deste procedimento com a própria vivência esquizofrênica de afastamento do mundo já foi apontada por mais de um autor. Naudin sugere que o psicopatologista, assim como o paciente tocado pela esquizofrenia, tenha que realizar uma "... epokhé em espelho" (2003, p.61) com seu paciente. Sass, por sua vez, mostra de maneira convincente como certos temas delirantes de pacientes esquizofrênicos brotam de suas indagações ontológicas - semelhantes, no limite, às de um psicopatologista -, comprometidas pela doença (2017, p.241-244). 
algum ponto sensível. Entretanto, dentro do patrimônio disponível ao psicopatologista está a capacidade de, mesmo sentindo essa raiva, descolar-se dela para examinar qual o significado que a produção de raiva possui na consciência do paciente. É possível que a raiva signifique um estado de humilhação intolerável, que necessita ser compartilhado para que possa ser minimamente suportado. Alternativamente, a raiva pode ser o produto de uma influência psicótica, sobre a qual o eu do paciente não tem nenhum controle. A diferença existente entre ambas as situações só pode ser identificada no caso de uma suspensão metodológica da experiência vivida na RA com o paciente.

Após a realização da RF, a intuição eidética é atingida, metodologicamente, pelo exercício de variação imaginativa comparativa. O psicopatologista, ao intuir diretamente a essência transtornada que brota em sua experiência com o paciente, procura executar uma comparação entre a essência que acaba de intuir e as demais essências psicopatológicas que conhece por experiência. Assim, o psicopatologista deve comparar aquilo que vive na coparticipação de uma essência maníaca com, digamos, a essência da ansiedade ou da inquietação. Ao executar esse ato de comparação, o psicopatologista aprimora sua capacidade de identificar a essência que intui. É pelo contraste e pela diferença que as essências psicopatológicas atingem sua maior visibilidade (JASPERS, 1953, p.37-38). Esta afirmação reitera a importância da experiência clínica no procedimento psicopatológico, pois este radica, em última análise, em um reconhecimento de estilos essenciais já de antemão sabidos pelo psicopatologista ou pela escola a que pertence. O diagnóstico essencial fenomenológico é, assim, um diagnóstico a posteriori, intimamente vinculado às categorias a priori da psicopatologia. Trata-se de um exercício imaginativo de natureza conservadora, que procura encontrar um objeto comparando com aqueles que já se conhece. Seu limite é a identificação da essência psicopatológica e, portanto, o reconhecimento daquilo que é invariante e generalizável na experiência humana.

Entretanto, um diagnóstico essencialista na vertente dialético-essencialista da fenomenologia deve levar à noção de essência um componente de tensão entre partes. $\mathrm{O}$ ato de RF necessário para a IE integral da situação é, em si, um fenômeno complexo, que também se subdivide em duas etapas praticamente concomitantes: a RF da TD e a RF da experiência do paciente. Retomando o exemplo acima, teríamos que essa dupla operação de TDs assim operaria: o psicopatologista, exilando-se da própria vivência de raiva, buscaria identificar i. como a raiva se situa na totalidade da relação e ii. como a essência da raiva se manifesta na totalidade da consciência do paciente. O elemento decisivo em 
ii. é o exame do modo como a vivência de humilhação/raiva ocupa simultaneamente as duas consciências em jogo, num fenômeno denominado interespacialidade (MESSAS, 2004). Por exemplo, no caso da agressividade surgir de um estranhamento psicótico, pode-se identificar como a raiva experimentada pelo psicopatologista não o preenche como um todo, deixando margem para o dito estranhamento. É como se ele não "acreditasse" profundamente em sua raiva. Simultaneamente, a IE conclui que a vivência no paciente é de um esvaziamento da consciência. Seria diferente - ainda no mesmo exemplo - de alguém que efetivamente esteja se sentindo humilhado. Neste caso, a força com que a humilhação invade a consciência produziria uma raiva mais invasora de ambas as interpessoalidades em RA. Por fim, e já trazendo em sua bagagem intelectual os conhecimentos obtidos pelos passos anteriores, dá-se o movimento redutor final. Nele, o psicopatologista pode exercer a IE da raiva do paciente ou como expressão de uma fragmentação psicótica desprovida de sentido antropológico (embora mantenha o sentido ontológico, como veremos), no primeiro caso, ou de como este paciente experiencia a raiva como máscara de um sentimento de humilhação, no segundo caso. Com estes passos, após as RFs, o psicopatologista tem diante de si, por IE, a essência da experiência perturbada de seu paciente e a composição de suas partes em relação dialética.

Para um diagnóstico propriamente fenomenológico, no entanto, mais uma etapa se faz necessária. Antes de passarmos à próxima etapa, no entanto, vale destacar que este procedimento serve tanto a uma entrevista inicial diagnóstica como ao seguimento do tratamento psicoterápico ou psiquiátrico. A diferença entre as duas aplicações reside apenas no fato de que, no seguimento, o psicopatologista já possui uma compreensão maior de seu paciente e, portanto, já consegue situar com mais rapidez as passagens de uma situação essencial a outra.

\subsection{A compreensão transcendental da estrutura}

O esforço que queremos fazer [...] é o de colocar o clínico em condições de voltar a sua atenção a um nível por certo invisível, mas não por isto não intuível ou não dedutível, ou seja, o nível ontológico (BALLERINI; DI PETTA, 2015, p.5).

Não se pode dizer estar o procedimento metodológico com isso completo, pois com a conclusão dessa passagem metodológica teremos apenas um diagnóstico essencial e não um diagnóstico psicopatológico fenomenológico integral. Esse nível de diagnóstico até poderia ser suficiente para os propósitos de uma psicopatologia geral, mas para suas 
implicações clínicas é necessário que ele seja subsumido em um nível mais profundo, que recupere as feições da estrutura individual na qual a essência patológica se manifesta. A reflexão identificadora da essência patológica completa-se por uma nova etapa, denominada compreensão transcendental (CT), que ambiciona incluir a compreensão da totalidade da estrutura existencial individual. Com a CT completa-se o diagnóstico psicopatológico fenomenológico.

Define-se aqui transcendental como o conjunto dos processos constituintes da existência que são necessariamente inacessíveis à consciência ${ }^{13}$.

A constituição transcendental da existência possui dois sentidos, de acordo com o plano da existência no qual ocorre, determinando dois objetos de conhecimento sincrônicos mas distintos.

a) O primeiro deles, estrutural ou ontológico, refere-se ao processo pelo qual a existência consciente forma seu fundamento pré-reflexivo de realidade, ou seja, sua constituição primária. Esta constituição primária é, por natureza, coconstituição, ou constituição interpessoal. O paradigma de patologia mental no qual há uma perda da constituição primária da realidade é a esquizofrenia. Nesta, o paciente (ou segmentos de sua existência) não compartilha(m) pré-reflexivamente do mundo ao qual pertence o psicopatologista. Por este motivo, a IE do psicopatologista encontra uma intuição de incompreensividade primária em seu contato com o paciente (HEINIMAA, 2003). O ato de compreensão transcendental, portanto, é um ato de intuição eidética - da região patológica - enriquecido por um ato de dedução transcendental, pelo qual o psicopatologista reconstrói a totalidade da existência individual de seu paciente, levando compreensividade fenomenológica à incompreensividade essencial. Isto se faz pelo exame das participações dialéticas relativas das zonas íntegras e das zonas psicopatológicas. O diagnóstico fenomenológico integral de uma esquizofrenia recupera, portanto, a dialética existente entre as zonas existenciais nas quais há a perda da coconstituição primária e zonas nas quais as experiências permanecem coconstituídas ditas normais. A simultaneidade dessas duas dimensões aparece com clareza na dificuldade de linguagem que certos esquizofrênicos têm para relatar suas experiências. A linguagem mundana, necessariamente coconstituída, mistura-se a experiências não partilháveis de linguagem, que fazem com que a comunicação do paciente, que brota do mundo coconstituído e tem ele como alvo, não seja compreensível pelo psicopatologista,

13 Também a noção de transcendentalidade adquire especificidades ao ser importada da filosofia para a psicopatologia (BINSWANGER, 2007; BLANKENBURG, 2013) 
que deve, dedutivamente, reconstruir seu sentido transcendental ontológico. A CT capta o sentido da patologia no indivíduo por uma análise da dialética das proporções com que a essência psicótica invade e toma a consciência. É também ela que atesta a presença da transformação patológica como compensação fenomenológica (SASS, 2014b). A IE reconhece a essência. A CT situa a essência nas camadas da existência individual.

Por meio da CT, o investigador, sem deixar de manter as raízes na simpatia ressonante com o paciente, procura, por meio de um exercício intuitivo específico, atingir o nível das condições de possibilidade da existência, região móvel na qual a dialética das proporções determina a qualidade, a dominância e a participação relativa das vivências conscientes. Este nível estrutural dá acesso ao conhecimento do indivíduo em particular. Este ato cognitivo, chamado de dedução transcendental (DT), é diferente da IE, que se fundamenta na variação imaginativa comparativa. As variações imaginativas atingem a essência de uma experiência, mas não suas condições de possibilidade. A DT se dá por uma intuição limite, que percute a própria textura da realidade do real. A DT dirige-se ao nível primordial da experiência, no qual as amarras da constituição de mundo são reveladas na existência individual factual pela sua potência de transformação temporal em simultaneidade necessária com a presença tácita de interpessoalidades. O objeto da DT é a expansão para todo o campo da existência da intuição essencial de que paciente e psicopatologista não compartilham segmentos do mesmo mundo. É justamente a este ponto de encontro no qual paciente e psicopatologista não partilham da constituição da realidade que se dá o nome de psicose. Este primeiro objeto de conhecimento, fornecido pela IE, é, portanto, tratado por uma dedução de proporções transcendentais que conduz pelos caminhos da reconstrução compreensiva da existência.

O primeiro objeto da CT define-se pela busca das relações dialéticas entre presença e ausência de coconstituição do real. Tem como o exemplo a compreensão de esquizofrenia que acima sugerimos. Trata-se, assim, de uma modalidade descontínua de CT. O objeto psicopatológico composto pela CT difere daquele identificado pela IE. A principal diferença entre os dois objetos é seu comportamento em relação ao tempo. A IE investe sobre um objeto estável e generalizável, ao passo que a CT investe e procura dar sentido a uma realidade em transformação (MESSAS, 2004). Por investigar uma estrutura existencial em movimento, deve ser refeita a todo o momento. Essa reconfiguração observada no paciente não recusa as características essenciais deste, já conhecidas pelo diagnóstico essencial, mas procura discriminar como os elementos eideticamente intuídos se comportam ao longo do tempo, ao ser incorporados pelo desenvolvimento biográfico. 
Alinham-se, assim, às noções clássicas de processo e desenvolvimento (JASPERS, 1997; ALONSO-FERNÁNDEZ, 1979). Este enriquecimento temporal proporcionado pela ação da CT sobre a IE permite que se inclua na agenda fenomenológica a compreensão dos sentidos da terapêutica (TAMELINI; MESSAS, 2017; MESSAS; TAMELINI, no prelo; TAMELINI; MESSAS, submetido), já que todo tratamento psicológico é uma modificação de proporções da existência ao longo do tempo. O procedimento dialéticoessencialista traz como critério para construção e avaliação das condutas terapêuticas a noção de recuperação (recovery) (TAMELINI; MESSAS, 2017); este conceito, marcado pelo pensamento dialético, substitui o entendimento da evolução do tratamento pela polaridade cura-cronificação. A noção de recuperação indica a dialética das proporções antropológicas envolvidas na melhora de uma paciente, deixando em segundo plano a enganosa avaliação semiológica do tratamento (GOROSTIZA; MANES, 2011).

b) sentido antropológico. O exame das relações dialéticas entre uma essência psicopatológica e a totalidade da existência determina uma segunda modalidade de CT, a modalidade proporcional. A modalidade proporcional reconstrói a experiência existencial do paciente em seu nível antropológico (CHARBONNEAU, 2010), no qual não há uma descontinuidade na coconstituição do real. O objeto deste nível de CT é o exame das dimensões pré-reflexivas da existência - temporalidade, espacialidade, interpessoalidades, corporeidade, identidade, etc - em suas relações dialéticas recíprocas, que determinam um estilo de proporções antropológicas. Os estilos de proporção antropológica caracterizam as psicopatologias que não comprometem a constituição interpessoal do real: são os ditos transtornos neuróticos ou de personalidade. Tomemos um exemplo de CT dialético-proporcional: a histeria caracteriza-se por uma excessiva relevância do outro nas experiências conscientes do paciente (MESSAS; ZORZANELLI; TAMELINI, no prelo). O balanço entre a autonomia do eu e a autonomia do outro valoriza desproporcionalmente a presença do outro na existência histérica. Na modalidade proporcional de $\mathrm{CT}$, esta efetua um ato cognitivo que reúne em uma única percepção transcendental a dimensão das proporções em jogo. Ela faz, por assim dizer, uma geometria das participações relativas de cada dimensão, permitindo o reconhecimento de um estilo antropológico típico (BLANKENBURG, 1982).

A compreensão transcendental (CT) é um ato de reconstrução intelectual-que exige do psicopatologista um elemento dedutivo, como definiu Minkowski (1999). O sentido de dedução aqui tem uma acepção específica. A dedução da CT não é a mesma da geometria, em termos de força e clareza. Por outro lado, depende, como na geometria, de 
um procedimento de encadeamento racional como sua garantia última - uma espécie de lógica existencial, por meio do qual um conhecimento com máximo de evidência sustenta o estabelecimento dos demais. A dedução fenomenológica transcendental caminha, como na geometria, de uma verdade estabelecida intuitivamente, ao estabelecimento de outras; porém, é necessário que, a todo momento, esta nova verdade tenha de ser testada nas experiências transtornadas do paciente, para ganhar estatuto de realidade $\mathrm{O}$ elemento dedutivo da $\mathrm{CT}$ é aquele que procura reconstruir o modo pelo qual a essência psicopatológica penetra na integralidade da existência, dominando-a ou não. Por exemplo, no caso de uma essência esquizofrênica, a CT procura detectar a força e extensão com que a incapacidade de constituir o real, típica da esquizofrenia, penetra na experiência de evidência natural do paciente. A gravidade da presença da essência esquizofrênica depende pois, de que esta perda da evidência do real ultrapasse, em proporção, a extensão da existência que se mantém ancorada na constituição do real. $\mathrm{O}$ diagnóstico fenomenológico tem, portanto, a ambição não apenas de admitir a presença de uma essência patológica, mas de examinar a volume e penetrância de sua manifestação na estrutura existencial individual. Por exemplo, em uma psicose catatônica, a fratura esquizofrênica domina toda a existência, ao passo que em uma paranoide, a tendência é de que penetre em apenas algumas de suas zonas de significação.

A CT é a porção mais problemática da aplicação do método; aquela que mais depende da experiência do psicopatologista e de seus talentos inatos. Por ser uma reconstrução erigida na consciência do examinador, é a mais distante do contato direto com o paciente e necessita, para sua validação, a confirmação dos achados psicopatológicos pelo paciente. A CT é um conhecimento cujo eixo é a dialética entre a ciência de primeira pessoa e a de segunda. Sendo, portanto, um conhecimento de terceira ordem (MESSAS, 2010), é aquele mais suscetível a erros na tradução das estruturas de outrem. Contudo, é o mais importante para, transcendendo a generalidade da essência, se atingir a clínica naquilo que tem de mais importante, a individualidade.

Entendida desta maneira, a CT não deixa de ser um estilo de hermenêutica, um conhecimento de segunda pessoa (FUCHS, 2010). Trata-se de uma hermenêutica, no entanto, na qual a linguagem atua como função exploratória de uma percepção totalizante de proporções antropológicas; uma hermenêutica, nas palavras de Binswanger (1994), prática. Cremos que a narratividade oferecida pela linguagem exerça um papel secundário na reconstrução exercida pela $\mathrm{CT}$. O nível primeiro no qual se dá a $\mathrm{CT}$, intuitivo e dedutivo, efetua-se sobretudo em uma região silenciosa do real, uma “...esfera que 
precede a linguagem e o pensamento" (BALLERINI; DI PETTA, 2015, p. 15) na qual a existência se enraíza, e da qual a linguagem recupera apenas a parte mais comunicável. Para nosso entendimento, toda hermenêutica linguística já é uma narrativa parcialmente afastada da interpessoalidade primordial da existência e mais próxima da língua do mundo, própria dos conhecimentos em terceira pessoa. A ciência em terceira pessoa é uma forma de conhecimento que se atinge a partir das evidências obtidas pela dialética dos conhecimentos de primeira e de segunda pessoa. Por isso, a necessária passagem deste nível dialético para o nível da linguagem clara da comunidade científica sofre de uma perda de validade. A publicidade da experiência relatada cientificamente é menos válida do que a cumplicidade da experiência composta em segunda pessoa sobre o fundamento da experiência subjetiva.

\section{Conclusão}

Pretendemos com este artigo apresentar em linhas gerais o procedimento diagnóstico fenomenológico de vertente dialético-essencialista. A sua validade é assegurada por uma compreensão da existência humana como fruto de grandes tensões existenciais insuperáveis e constituintes da natureza do existir. Duas são essas movimentações dialéticas originais: a tensão entre o individual e o geral (MESSAS, 2014) e entre o movimento, que singulariza a existência, e a estabilidade, que a conduz para a generalidade (MESSAS, 2010). Em obras anteriores, apresentamos exemplos clínicos destas tensões originais. Nesta contribuição, oferecemos o detalhamento metodológico que permite sua visão científica e, a partir dela, a construção de uma terapêutica que respeite suas linhas de força. Esperamos com isto colaborar para a agenda psicopatológica de três maneiras fundamentais. A primeira delas, com a realização do ato diagnóstico, o procedimento inicial de toda exploração psicopatológica. Em segundo lugar, com a renovação da prática terapêutica, tanto em sua esfera psicológica como na dimensão farmacoterápica, na qual os psiquiatras se implicam de modo mais direto. Por fim, mas com mesmo grau de importância, o método por nós apresentado pretende se oferecer como instrumento para a pesquisa dos fundamentos fisiológicos das experiências psicopatológicas: a agenda futura de uma neurociência que procure de fato representar a existência humana não pode prescindir de uma contribuição fenomenológica. 


\section{Referências}

ALONSO-FERNÁNDEZ, F. Fundamentos de La Psiquiatria Actual. 3. ed. Madrid: Editorial Paz Montalvo, 1979.

AMATUZZI, M. Psicologia fenomenológica: uma aproximação teórica humanista. Estudos de Psicologia, Campinas, v. 26, n. 1, p. 93-100, jan./mar. 2009.

ANDRADE, C. C.; HOLANDA, A. F. Apontamentos sobre pesquisa qualitativa e pesquisa empírico-fenomenológica. Estudos de Psicologia, Campinas v. 27, n. 2, p. 259-268, abr./jun. 2010.

APA. Diagnostic and Statistical Manual of Mental Disorders V. 5th. Arlington. American Psychiatric Publishing, 2013.

BACA-GARCIA, E. et al. Diagnostic stability of psychiatric disorders in clinical practice. Br J Psychiatry, London, v. 190, n. 3, p. 210-6, mar. 2007.

BALLERINI, A. Lettera alla Redazione. Rivista Comprendre, Firenze, v. 14, p. 32-35. 2004.

BALLERINI, A.; DI PETTA, G. Oltre e di là dal mondo: l'essenza della schizofrenia. Fenomenologia e psicopatologia. Rome: Giovanni Fioriti Editore, 2015.

BANZATO, C. E. M.; ZORZANELLI, R. Superando a falsa dicotomia entre natureza e construção social: o caso dos transtornos mentais. Rev. latinoam. psicopatol. fundam., São Paulo, v. 17, n. 1, p. 100-113, mar. 2014.

BASSO, E. From the Problem of the Nature of Psychosis to the Phenomenological Reform of Psychiatry. Historical and Epistemological Remarks on Ludwig Binswanger's Psychiatric Project. Medicine Studies, Netherlands, v. 3, n. 4, p. 215-232, nov. 2012.

BINSWANGER, L. Schizophrenie. Pfullinger: Günther Neske Verlag, 1957.

BINSWANGER, L. Melancholie und Manie. Phänomenologische Studien. Pfüllingen: Neske, 1960.

BINSWANGER, L. Ausgewählte Werke, vol. III: Vorträge und Aufsätze. Heidelberg: Asanger, 1994.

BINSWANGER, L. Sobre la fenomenologia. In: La curacíón infinita. 1. ed. Buenos Aires: Adriana Hidalgo Editora, 2007. p. 279-341.

BINSWANGER, L. Três Formas da Existência Malograda. Rio de Janeiro: Zahar Editores, 1977.

BINSWANGER, L. Melanconia e mania. Studi fenomenologici Torino: Bollati Boringhieri, 2006.

BLANKENBURG, W. Phenomenology and Psychopathology. Journal of Phenomenological Psychology, Leiden, v. 11, n. 2, p. 50-78, Fall. 1980.

BLANKENBURG, W. A dialectical conception of anthropological proportions. In: DE KOONIG, A.; JENNER, F. (Ed.). Phenomenology and Psychiatry. London, Toronto and Sydney: Academic Press, 1982. p.35- 50. 
BLANKENBURG, W. La pérdida de la evidencia natural: una contribución a la psicopatología de la esquizofrenia. 1. ed. Santiago do Chile: Ediciones Universidad Diego Portales, 2013.

BLEULER, E. Les Problèmes de la schizoïdie et de la syntonie. L'information psychiatrique, v. 87, n. 1, p. 37-51, févr. 2011.

CALVI, L. Epochè, prassi mimetica e neuroni specchio. Rivista Comprendre, Firenze, v. 19, p. 34-43. 2009.

CHARBONNEAU, G. Introduction à la psychopathologie phénoménologique. Paris: MJW Fédition, 2010.

COSTA, C. et al. Phenomenology of atmospheres. The felt meanings of clinical encounters. Journal of Psychopathology, Ospedaletto (Pisa), v. 20, n. 4, p. 351-357. 2014.

DE MONTICELLI, R. L'ascesi filosofica. Studi sul temperamento platonico. Milano: Feltrinelli, 1996.

DEPRAZ, N.; VARELA, F. J.; VERMERSCH, P. À l'épreuve de l'expérience. Pour une pratique phénoménologique. Bucarest: ZETA Books, 2011.

DI PETTA, G. Gruppoanalisi dell'esserci. Tossicomania e terapia delle emozioni condivise. Milano: Franco Angeli, 2006.

DI PETTA, G. Nel nulla esserci. Il vuoto, la psicosi, l'incontro. Rome: Edizioni Universitarie Romane, 2012.

FERNANDEZ, A. V. The subject matter of phenomenological research: existentials, modes, and prejudices. Synthese, Netherlands, v. 194, n. 0, p. 3543-3562, sept. 2017.

FEIJOO, A. M. L. C.; MATTAR, C. M. A Fenomenologia como Método de Investigação nas Filosofias da ExistÊncia e na Psicologia. Psicologia: Teoria e Pesquisa, Brasília, v. 30, n. 4, p. 441-447, out./dez. 2014.

FINLAY, L. A Dance Between the Reduction and Reflexivity: Explicating the "Phenomenological Psychological Attitude". Journal of Phenomenological Psychology, Leiden, v. 39, n. 1, p. 1-32, jan. 2008.

FORGHIERI, Y. C. Psicologia Fenomenológica: fundamentos, método e pesquisas. 2. ed. São Paulo: Pioneira, 1993.

FUCHS, T. Subjectivity and intersubjectivity in psychiatric diagnosis. Psychopathology, Basel, v. 43, n. 4, p. 268-74, june. 2010.

FUKUDA, L. E.; TAMELINI, M. G. A compreensão psicológica jasperiana revisitada sob a perspectiva da psicopatologia fenomenológica. Psicopatologia Fenomenológica Contemporânea, São Paulo, v. 5, n. 2, p. 160-184, 2016.

GABBANI, C.; STANGHELLINI, G. What kind of objectivity do we need for psychiatry? A Commentary to Oulis's Ontological assumptions in psychiatric taxonomy. Psychopathology, Basel, v. 41, n. 3, p. 203-204, april. 2008. 
GALBUSERA, L.; FELLIN, L. The intersubjective endeavor of psychopathology research: methodological reflections on a second-person perspective approach. Front Psychol, Lausanne, v. 5, não tem número, article 1150, p. 1-14, oct. 2014.

GALLAGHER, S.; ZAHAVI, D. La Mente Fenomenológica. 2. ed. Madrid: Alianza Editorial, 2013.

GARCÍA, P. E. The relationship between Philosophy and Neuroscience from Dan Zahavi's Phenomenology of Mind. In: GARGIULO, P. Á.; MESONES-ARROYO, H. L. (Ed.).

Psychiatry and Neuroscience Update - Vol. II: A Translational Approach. Switzerland: Springer, 2017. p. 21-36.

GIORGI, A. The Descriptive Phenomenological Method in Psychology: A Modified Husserlian Approach. Pittsburgh: Duquesne University Press, 2009.

GOROSTIZA, P. R.; MANES, J. A. Misunderstanding psychopathology as medical semiology: an epistemological enquiry. Psychopathology, Basel, v. 44, n. 4, p. 205-215, may. 2011.

GOZÉ, T.; NAUDIN, J. Discussing Rümke's "Praecox Feeling” from the clinician's experience of schizophrenic contact. Psicopatologia Fenomenológica Contemporânea, São Paulo, v. 6, n. 2, p. 112-123. 2017.

GRUBE, M. Towards an empirically based validation of intuitive diagnostic: Rümke's 'praecox feeling' across the schizophrenia spectrum: preliminary results. Psychopathology, Basel, v. 39, n. 5, p. 209-217, aug 2006.

HEINIMAA, M. Incomprehensibility. In: FULFORD, B. et al. (Eds.). Nature and narrative. An introduction to the new philosophy of psychiatry. Oxford, UK: Oxford University Press, 2003. p. 217-230.

HEIDEGGER, M. Sein und Zeit. 19. ed. Halle: Niemeyer Verlag, 2001.

HELZER, J. E. et al. Reliability of psychiatric diagnosis. II. The test/retest reliability of diagnostic classification. Arch Gen Psychiatry, Chicago, v. 34, n. 2, p. 136-41, feb. 1977.

HUSSERL, E. Meditaciones Cartesianas. 2. ed. Mexico: Fondo de Cultura Economica, 2004.

JABLENSKY, A.; KENDELL, R. E. Criteria for Assessing a Classification in Psychiatry. In: MAJ, M. et al. (Ed.). Psychiatric Diagnosis and Classification. Chichester, United Kingdom: John Wiley \& Sons, Ltd, 2002. p. 1-24.

JABLENSKY, A. Psychiatric classifications: validity and utility. World Psychiatry, Milan, v. 15, n. 1, p. 26-31, feb. 2016.

JASPERS, K. Strindberg et Van Gogh, Swedenborg-Hölderlin - Etude Psychiatrique Comparative. Paris: Les Editions de Minuit, 1953.

JASPERS, K. The phenomenological approach in psychopathology. Brit J Psychiat, London, v. 114, n. 516, p. 1313-1323, nov. 1968.

JASPERS, K. General Psychopathology. Baltimore: The Johns Hopkins University Press, 1997.

KENDELL, R.; JABLENSKY, A. Distinguishing between the validity and utility of psychiatric diagnoses. Am J Psychiatry, Arlington, v. 160, n. 1, p. 4-12, jan. 2003. 
KENDLER, K. S. The nature of psychiatric disorders. World Psychiatry, Milan, v. 15, n. 1, p. 5-12, feb. 2016.

KIMURA, B. L'entre. Une approche phenomelogique de la schizophrenie. Edição: não tem indicação no livro. Grenoble: Jérôme Millon, 2000.

KRAUS, A. Modes d'existence des hystériques et des mélancolique. In: FÉDIDA, P.; SCHOTTE, J. (Eds.). Psychiatrie et existence. 3 ed. Grenoble: Jérôme Million, 1991. p. 231246.

KRAUS, A. Phenomenological-Anthropological Psychiatry. In: HELMCHEN, H. et al. (Ed.). Contemporary Psychiatry. 1 ed. Berlin, Heidelberg, New York: Springer, 2001. p. 339-356.

KRAUS, A. How can the phenomenological anthropological approach contribute to diagnosis and classification in psychiatry? In: FULFORD, K. et al. (Ed.). Nature and Narrative: an introduction to the new philosophy of psychiatry. Oxford: Oxford University Press, 2003. p. $119-216$

LEAL, E. M.; SERPA JR, O. D. Acesso à experiência em primeira pessoa na pesquisa em Saúde Mental. Ciênc. saúde coletiva, Rio de Janeiro, v. 18, n. 10, p. 2939-48, junho. 2013.

MERLEAU-PONTY, M. The visible and the invisible. Evanston: Northwestern University Press, 1968.

MERLEAU-PONTY, M. Fenomenologia da Percepção. 4. ed. São Paulo: Martins Fontes, 2011.

MESSAS, G.; FULFORD, K. W.; STANGHELLINI, G. The contribution of human sciences to the challenges of contemporary psychiatry. Trends Psychiatry Psychother, Porto Alegre, v. 39, n.4, p. 229-231, oct./dec. 2017.

MESSAS, G. P.; TAMELINI, M.G.; CUTTING, J. A meta-analysis of the core essence of psychopathological entities: an historical exercise in phenomenological psychiatry. Hist Psychiatry, London, v. 28, n. 4, p. 473-481, dec. 2017.

MESSAS, G. P. Psicopatologia e transformação: um esboço fenômeno-estrutural. 1. ed. São Paulo: Casa do Psicólogo, 2004.

MESSAS, G. P. Ensaio Sobre a Estrutura Vivida - Psicopatologia Fenomenológica Comparada. 1. ed. São Paulo: Editora Roca, 2010.

MESSAS, G. P. A noção de estrutura na psicopatologia/psicologia fenomenológica. Uma perspectiva epistemológica. In: RODRIGUES, A. et al. (Ed.). Psicopatologia Conceitual. São Paulo: Editora Roca, 2012. p. 51-62.

MESSAS, G. P. Psicose e embriaguez - psicopatologia fenomenológica da temporalidade. 1. ed. São Paulo: Editora Intermeios, 2014.

MESSAS, G. P.; TAMELINI, M. G. The Pragmatic Value of Notions of Dialectics and Essence in Phenomenological Psychiatry and Psychopathology. Thaumàzein - Rivista di Filosofia, Verona, no prelo.

MESSAS, G. P.; ZORZANELLI, R.; TAMELINI, M. G. The Life-World of Hysteria. In: STANGHELLINI, G. e FERNANDEZ, A. (Ed.). Oxford Handbook of Psychopathology. Oxford: Oxfoird University Press, no prelo. 
MINKOWSKI, E. EI Tiempo Vivido. 1. ed. México, D.F.: Fondo de Cultura Económica, 1973.

MINKOWSKI, E. Traité de psychopathologie. Le Plessis-Robinson: Institut Synthélabo, 1999.

MINKOWSKI, E. La Esquizofrenia: psicopatologia de los esquizóides y los esquizofrénicos. 1. ed. México, D. F.: Fondo de Cultura Económica, 2000.

NAUDIN, J. L' usage de la réduction husserlienne comme méthode d'investigation dans l'expérience psychiatrique. Revue Alter, Paris, v. 11, p. 257-264. 2003.

NORDGAARD, J.; SASS, L.; PARNAS, J. The psychiatric interview: validity, structure, and subjectivity. Eur Arch Psychiatry Clin Neurosci, Berlin/Heidelberg, v.263, n.4, p. 353-364, jun. 2013.

OULIS, P. Ontological assumptions of psychiatric taxonomy: main rival positions and their critical assessment. Psychopathology, Basel, v. 41, n. 3, p. 135-40, jan. 2008.

PETHÕ, B. et al. Validity of reliability: comparison of interrater reliabilities of psychopathological symptoms. J Nerv Ment Dis, Hagerstown, v. 195, n. 7, p. 606-13, jul 2007.

PETRELLI, R. Fenomenologia: teoria, método e prática. Goiânia: Editora da UCG, 2005.

RATCLIFFE, M. Feelings of Being: Phenomenology, Psychiatry and the Sense of Reality. 1. ed. Oxford: Oxford University Press, 2008.

RATCLIFFE, M. Empathy without Simulation. In: SUMMA, M.; et al. (Ed.). Imagination and Social Perspectives: Approaches from Phenomenology and Psychopathology. London: Routledge, 2017. Disponível em: <https://www.academia.edu/26921176/Empathy_without_Simulation>. Acesso em: 24 july. 2018.

ROVALETTI, M. L. De la hermenéutica del relato a la hermenéutica de la recepción. In: COLOQUIO LATINOAMERICANO DE FENOMENOLOGÍA, I, 2002. Bogotá. Actas... Lima: Pontiicia Universidad Católica del Perú, 2003. p. 347-358.

RÜMKE, H. C. The nuclear symptom of schizophrenia and the praecox feeling. History of Psychiatry, London, v. 1, n. 3, p. 331-341, sept. 1990.

SASS, L. Self-disturbance and schizophrenia: structure, specificity, pathogenesis (Current issues, New directions). Schizophr Res, Amsterdam, v. 152, n. 1, p. 5-11, jan. 2014a.

SASS, L. Explanation and description in phenomenological psychopathology. Journal of Psychopathology, Ospedaletto (Pisa), v. 20, n. 4, p. 366-376, 2014 b.

SASS, L. Madness and Modernism. Insanity in the light of modern art, literature, and thought (revised edition). Oxford: Oxford University Press, 2017.

SASS, L.; PIENKOS, E. Space, Time, and Atmosphere A Comparative Phenomenology of Melancholia, Mania, and Schizophrenia, Part II. Journal of Consciousness Studies, Exeter, v. 20, n. 7-8, p. 131-152, 2013.

SASS, L. et al. EAWE: Examination of Anomalous World Experience. Psychopathology, Basel, v. 50, n. 1, p. 10-54, apr. 2017. 
SCHELER, M. The nature of sympathy. London: Routledge and Kegan Paul, 1954.

SERPA JR, O. D. Experiência, narrativa e conhecimento: a perspectiva do psiquiatra e a do usuário. Physis, Rio de Janeiro, v. 24, n. 4, p. 1053-1077, 2014.

SPIEGELBERG, H. Phenomenology Through Vicarious Experience. In: STRAUS, E. W. (Ed.). Phenomenology: Pure and Applied. Pittsburgh: Duquesne University, 1964. p. 105-126.

STANGHELlinI, G. Disembodied Spirits and Deanimated Bodies: The Psychopathology of Common Sense. Oxford: Oxford University Press, 2004.

STANGHELLINI, G. The grammar of the psychiatric interview. A plea for the second-person mode of understanding. Psychopathology, Basel, v. 40, n. 2, p. 69-74, feb. 2007.

STANGHELLINI, G.; MANCINI, M. The Therapeutic Interview in Mental Health: A Values-Based and Person-Centered Approach. Cambridge: Cambridge University Press, 2017.

TAMELINI, M. G.; MESSAS, G. P. Phenomenological psychopathology in contemporary psychiatry: interfaces and perspectives. Rev. latinoam. psicopatol. Fundam, São Paulo, v. 20, n. 1, p. 165-180, mar. 2017.

TAMELINI, M.G.; MESSAS, G. P. Pharmacological treatment of schizophrenia in light of phenomenology. Philosophy, Psychiatry, \& Psychology, submetido.

TATOSSIAN, A. A Fenomenologia das Psicoses. 1. ed. São Paulo: Editora Escuta, 2006.

TELLENBACH, H. La Melancolia. Visión histórica del problema: tipologia, patogenia y clinica. 2. ed.Madrid: Ed. Morata, 1975.

TELLENBACH, H. Tasting and Smelling-Taste and Atmosphere-Atmosphere and Trust. Journal of Phenomenological Psychology, Leiden, v. 12, n. 2, p. 221-230, jan. 1981.

TELLENBACH, H. Analyse phénomenologique de la rencontre interhumaine dans le Dasein normal et pathologique. In: COURTINE, J. F. (Ed.). Figures de la Subjectivité. Approches Phénomenologiques et Psychiatriques. Paris: Éditions du Centre National de Recherche Scientifique, 1992. p.109-118.

VAN PRAAG, H. M. Reconquest of the subjective. Against the waning of psychiatric diagnosing. The British Journal of Psychiatry, London, v. 160, n. 2, p. 266-271, feb. 1992.

Recebido em: 11 de fevereiro de 2018.

Aceito em: 02 de julho 2018. 